\title{
COMPORTAMENTO FISIOLÓGICO DE GOIABEIRA SERRANA QUANDO MULTIPLICADA POR MERGULHIA DE CEPA
}

\author{
M.S. MIEĹKE; J.C. FACHINELLO'; J.C. NACHTIGAL; B. MATIUZ; L. ENDRÉ ${ }^{1}$ \\ Departamento de Fitotecnia, FAEM/UFPEL. C.P. 354, CEP:96010-900-Pelotas, RS. \\ B.GOMES dos SANTOS FILHO' \\ Departamento de Biologia, IB/UFPEL, C.P. 354, CEP:96010-900-Pelotas, RS.
}

\begin{abstract}
RRSUMO: Com o objetivo de estudar alguns fatores fisiológicos envolvidos na formação e desenvolvimento de raízes em mudas de goiabeira serrana (Feljoa sellowiana Berg), multiplicadas por mergulhia de cepa, foi realizado um experimento em Pelotas-RS, com mudas decepadas em julho de 91 e sobre as quais foi realizada amontoa em outubro de 91. A avaliação foi feita em agosto de 92, sendo observadas as variáveis: teor de clorofila total, área foliar, número e diâmetro de brotaçōes, número e percentagem de brotaçōes enraizadas e peso da matéria seca das raízes. As variáveis teor de clorofila, área foliar e diâmetro médio das brotaçōes não apresentaram influência sobre a matéria seca das rázes. 0 incremento no número de brotaçōes causou um aumento no número de brotações enraizadas, entretanto, não apresentou influencia na percentagem de brotaçōes enraizadas. $O$ aumento no número de brotaçōes por cepa ocasionou um decréscimo em seu diâmetro médio. É demonstrado que é possível multiplicar plantas de goiabeira serrana através de mergulhia de cepa.

Descritones: Feijoa sellowiana Berg, goiabeira serrana, mergulhia, fisiologia vegetal.
\end{abstract}

\section{PHYSIOLOGICAL BEHAVIOR OF FGIJOA MULTTPLIED BY STOOL LAYRING}

\begin{abstract}
The aim of this research was to study some physiological factors involved in root growth and development in sprouts of feijoa Feijoa sellowiana Berg., multiplied by stool layring. The experiment was conducted in Pelotas,RS, Brazil, using sprouts cut in July 91, which were covered with soil in October 91. In August 92 the following variables were evaluated: total chlorophyll content, leaf area, stool number and diameter, number and percentage of rooted stools and root dry-matter weight. The variables chlorophyll content, leaf area and stool average diameter, did not show influence on root dry matter. The increase in number of stools caused an increase in the number but not in the percentage of rooted stools. The increase in stool number per plant caused a decrease in stool average diameter. It is demonstrated that it is possible to multiply feijoa plants through stool layring.
\end{abstract}

Key Words: Feijoa sellowiana Berg., feijoa, stool layring, plant physiology.

\section{INTRODUÇÃo}

A Faculdade de Agronomia Eliseu Maciel, em conjunto com o Centro Nacional de Pesquisas de Frutas Tropicais/EMBRAPA, vem desenvolvendo esforços no sentido de obter material e técnicas que permitam o cultivo comercial da goiabeira serrana (Feijoa sellowiana Berg.) no sul do Brasil. Os trabalhos realizados dizem respeito principalmente ao melhoramento genético e propagação vegetativa (RASEIRA \& RASEIRA, 1989; FACHINELLO \& NACHTIGAL (1992).

Entre as técnicas de propagação vegetativa de plantas, a multiplicação de mudas por mergulhia de cepa é uma prática muito utilizada para a produção comercial de porta-enxertos de macieira, marmeleiro, cerejeira, ameixeira e outras

\footnotetext{
' Bolsista do CNPq.
} 
especies (DRIESSEN \& SOUZA FILHO, 1986; HARTMANN \& KESTER, 1990; QUAMME \& BROWNLEE, 1990).

Trabalhandocom "seedlings" de goiabeira serrana, FACHINELLO \& NACHTIGAL (1992) obtiveram uma média de 6,66 mudas por cepa, utilizando plantas decepadas a $10 \mathrm{~cm}$ de altura e amontoa realizada 2 meses após. Observaram uma grande variabilidade quanto ao número de raízes por brotação e o comprimento e diâmetro das brotações entre as diferentes plantas utilizadas.

QUAMME \& BROWNLEE (1990), trabalhando com porta-enxertos clonais de macieira (Malus sp.), multiplicados através de mergulhia de cepa, verificaram que a produção de brotações enraizadas está mais relacionada com a capacidade interna das plantas em emitir raízes do que com o número total de brotações. Verificaram também que naqueles clones que produziram maior número de brotações enraizadas, estas tinham o sistema radicular mais bem formado.

Trabalhos realizados com estacas semilenhosas de goiabeira serrana também fazem referência à grande variabilidade que ocorre $\mathrm{em}$ plantas individuais quanto aos percentuais de enraizamento obtidos (IVEY, 1979; KULIEV \& BABAEV, 1989).

O presente trabalho teve por objetivo estudar e quantificar alguns fatores fisiológicos envolvidos na formação e desenvolvimento de raizes em mudas de goiabeira serrana multiplicadas por mergulhia de cepa.

\section{MATERIAL E MÉTODOS}

O experimento foi realizado no Centro Nacional de Pesquisa de Fruteiras de Clima Temperado/EMBRAPA e na Faculdade de Agronomia Eliseu Maciel/UFPEL, em Pelotas, RS, no periodo compreendido entre 06/91 a 08/92.

0 solo do local onde foi instalado o experimento pertence a unidade de mapeamento Camaquã, classificado como Podzólico Vermelho amarelo, textura argilosa, relevo ondulado com substrato de granito (BRASIL, 1973). O clima da região é do tipo $C$ fa, segundo classificação de Koeppen. Dados de temperatura e precipitação durante o periodo de realização do experimento são apresentados na Figura 1.

Foram utilizados 30 "seedlings", com aproximadamente 3 anos de idade, decepados em julho de 1991 e amontoa realizada em outubro do mesmo ano. A avaliação do experimento foi reali- zada em agosto de 1992, dez meses após a amontoa; sendo observadas as seguintes variáveis: teor de clorofila total, área foliar, número de brotações por planta, número e percentagem de brotações enraizadas por planta, diâmetro das brotações e matéria seca das raizes. As análises de clorofila foram realizadas em folhas de 15 plantas, segundo ARNON (1949). A área foliar foi estimada através das medidas das áreas de amostras, tomadas ao acaso, compostas de $\mathbf{4 0}$ folhas por planta, utilizando-se um medidor automático de área foliar modelo LI-3000.

Os resultados foram expressos pelas médias e coeficientes de variação das diferentes variáveis avaliadas, além de regressões lineares simples entre teor de clorofila, área foliar, número de brotações por planta e diâmetro médio das brotações $\mathrm{x}$ número de brotações, número $\mathrm{e}$ percentagem de brotações enraizadas e matéria seca das raízes. Foi também realizada uma comparação entre o diâmetro das brotações enraizadas e nãoenraizadas, utilizando-se o delineamento experimental inteiramente ao acaso, com 30 repetições por tratamento; sendo a comparação múltipla de médias realizada através do teste de Tukey, ao nível de $1 \%$ de probabilidade.

\section{RESULTADOS E DISCUSSÃO}

As Figuras 2 a 8 apresentam os resultados obtidos com as plantas estudadas, assim como as médias e coeficientes de variação das diferentes variáveis avaliadas. Os maiores coeficientes de variação foram encontrados para as variáveis matéria seca das raízes, número de brotações enraizadas, número de brotações e percentagem de brotações enraizadas; $80,95 \%, 53,31 \%, 45,42 \%$ e $37,90 \%$, respectivamente. As variáveis teor de clorofila, área foliar e diâmetro das brotações apresentaram coeficientes de variação sempre inferiores a $20 \%$.

$\mathrm{Na}$ revisão de literatura realizada não foram encontrados trabalhos relacionando teor de clorofila com enraizamento. Entretanto, sabe-se que o teor de clorofila está diretamente relacionado com o processo fotossintético e acúmulo de carbohidratos, necessários a formação de novas raízes. Segundo HARTMANN \& KESTER (1990), parece existir uma forte relação entre a nutrição da planta-matriz, particularmente na relação $\mathrm{C} / \mathrm{N}$, e a emissão de raízes em estacas. $O$ excesso de carbohidratos origina raízes finas e delgadas, enquanto que 0 excesso de $\mathbf{N}$ produz estacas flácidas e suscetíveis à podridões, com excesso de vigor. 


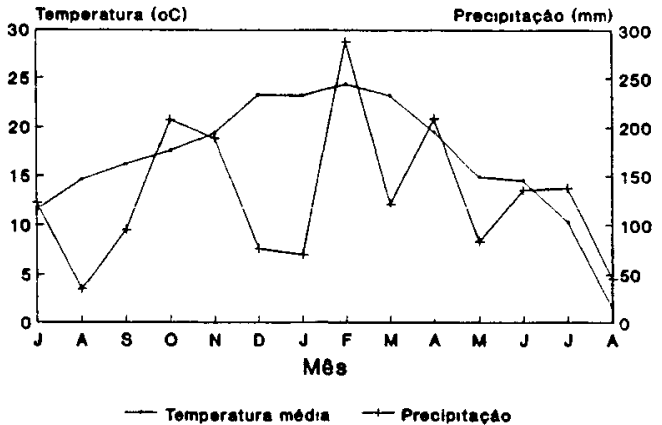

Figura 1 - Temperatura média e precipitação durante o período de execução do experimento (Jul/91 a Ago/92), Pelotas, RS.

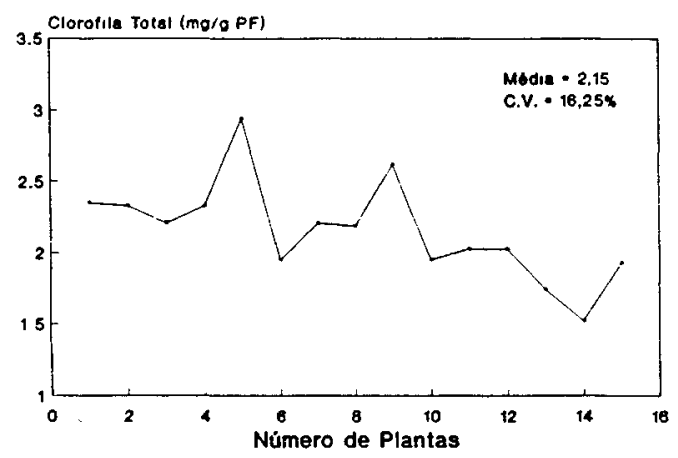

Figura 2 - Teores de clorofila total, medido em 15 plantas de goiabeira serrana multiplicadas por mergulhia de cepa.

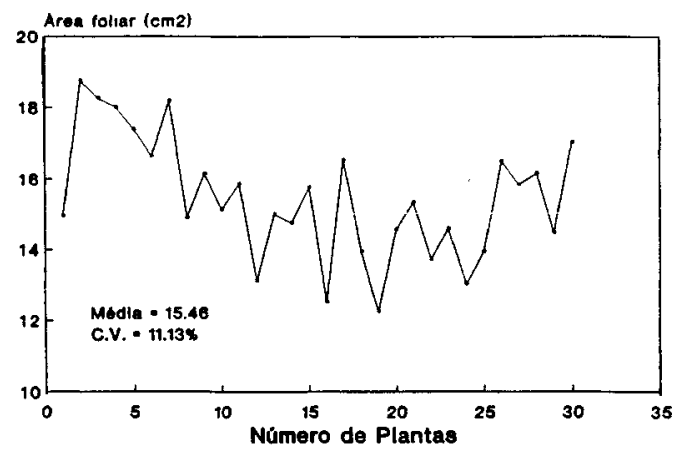

Figura 3 - Área foliar de plantas de goiabeira serrana multiplicadas por mergulhia de cepa.

Sci. agric., Piracicaba, 51(1):21-27, jan./abr., 1994

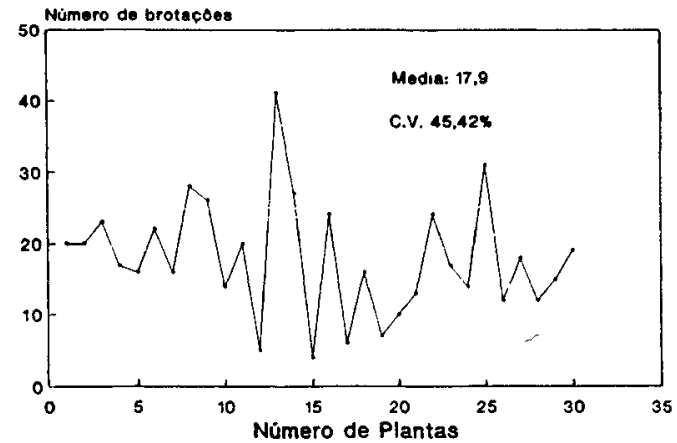

Figura 4 - Número de brotações em plantas de goiabeira serrana multiplicadas por mergulhia de cepa.

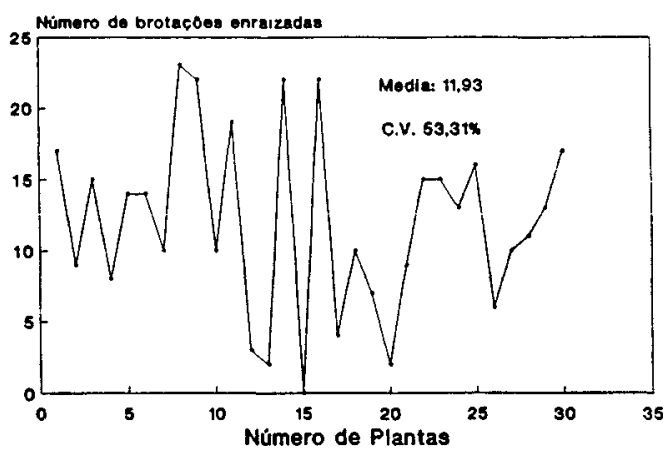

Figura 5 - Número de brotações enraizadas em plantas de goiabeira serrana multiplicadas por mergulhia de cepa.

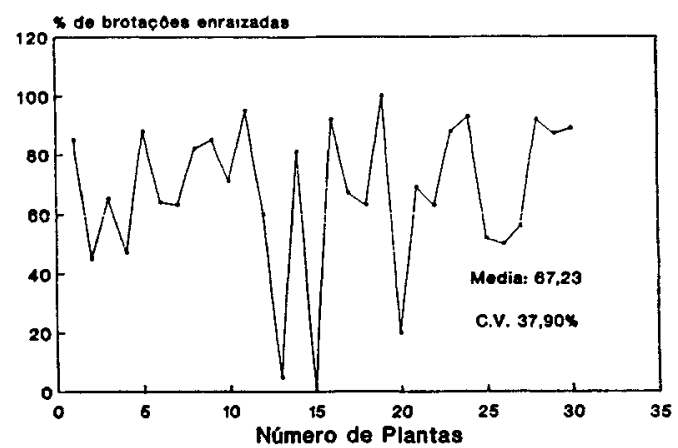

Figura 6 - Percentagem de brotações enraizadas em plantas de goiabeira serrana multiplicadas por mergulhia de cepa. 
Entretanto, um equilibrio com baixo conteúdo de $\mathbf{N}$ e alto conteúdo de carbohidratos parece favorecer o enraizamento. Além disso, o teor de clorofila é dependente do genótipo de cada planta e vem sendo utilizado, juntamente com a área foliar, para a seleção de porta-enxertos clonais quanto ao vigor dos mesmos (PAL et al., 1981). Porta-enxertos vigorosos possuem sistema radicular mais desenvolvido e abundante.

A Figura 2 apresenta os valores de clorofila total, nas 15 plantas onde foram avaliados. Foram observadas variações desde 1,52 até 2,94 $\mathrm{mg} / \mathrm{gPF}$, entretanto, não foram encontradas correlações significativas entre esta variável e o número de brotações, número e percentagem de brotações enraizadas e matéria seca das raízes.

A área das folhas é outro parâmetro relacionado diretamente com 0 processo fotossintético, uma vez que diz respeito à superfície de captação da luz e estrutura morfológica da folha (BENINCASA, 1988). DUBOIS (1990), trabalhando com estacas semilenhosas de roseiras anãs (cultivares para vaso), observou que estacas com maior área foliar apresentaram maior número de raízes; entretanto, não encontrou correlação significativa entre área foliar $x$ percentual de enraizamento. No presente trabalho foram encontradas variações desde 12,25 até $18,75 \mathrm{~cm}^{2}$ para área das folhas entre as $\mathbf{3 0}$ plantas utilizadas (Figura 3). Apesar das variações verificadas, não foram encontradas correlações lineares significativas entre área foliar e as demais variáveis estudadas.

Com relação aos dados acima apresentados, deve-se salientar que a mergulhia $\mathfrak{\epsilon}$ uma prática de propagação vegetativa onde as brotações a serem enraizadas permanecem ligadas à planta-matriz e são supridas constantemente de elementos minerais do solo, cuja absorção, transporte e redistribuição estão direta ou indiretamente ligadas ao processo fotossintético. Assim, estas brotações apresentaram um equilíbrio na relação $C / N$ superior àquele encontrado $\mathrm{em}$ estacas, e, uma vez que não foram utilizadas substâncias promotoras do enraizamento (ácido indolbutírico), é bem provável que as variações ocorridas foram dependentes da capacidade interna das plantas utilizadas em sintetizar, em maior ou menor quantidade, as substâncias envolvidas no processo de enraizamento (auxinas e cofatores) (HARTMANN \& KESTER, 1990).

As variáveis número de brotações e número de brotações enraizadas (Figura 4 e 5) apresentaram variações de 4 até 41 e de 0 até 23 , respectivamente, enquanto a percentagem de brotações enraizadas (Figura 6 ) variou de 0 até $100 \%$. Foram encontradas correlações lineares significativas entre número de brotações e número de brotações enraizadas, enquanto que a correlação entre o número de brotações e percentagem de brotações enraizadas não foi significativa. Estes dados indicam que um maior número de brotações por planta teve como consequência maior número de brotações enraizadas, existindo uma variação muito grande quanto à percentagem de brotações enraizadas por planta. A grande variação na percentagem de brotações enraizadas está de acordo com os dados apresentados por vários autores quanto à variabilidade de resultados obtidos no enraizamento de estacas semilenhosas ou cepas desta espécie quando originadas de diferentes plantas matrizes (IVEY, 1979; FACHINELLO \& NACHTIGAL, 1992).

Embora a multiplicação de plantas através de mergulhia de cepa seja uma prática de propagação vegetativa bastante citada em textos técnicos (ADRIANCE \& BRISON, 1955; SILVA, 1985; DRIESSEN \& SOUZA FILHO, 1986; HARTMANN \& KESTER, 1990), foram poucos os trabalhos científicos encontrados apresentando dados experimentais (QUAMME \& BROWNLEE, 1990; FACHINELLO \& NACHTIGAL, 1992). MOHAMED (1984) considera que a mergulhia só deve ser empregada quando houver dificuldade na utilização de outros métodos de propagação vegetativa e cita várias frutíferas tropicais que podem ser multiplicadas desta forma. HARTMANN \& KESTER (1990), por outro lado, citam várias espécies propagadas comercialmente por este método, sendo o seu uso praticamente limitado à multiplicação de porta-enxertos clonais.

Observando mais atentamente a Figura 6, nota-se que a grande maioria das plantas avaliadas apresentou percentuais de brotações enraizadas acima de $50 \%$, resultados superiores àqueles obtidos por outros autores utilizando estacas semilenhosas (IVEY, 1979; KULIEV \& BABAEV, 1983; COUTINHO et al., 1991; DUARTE, 1991). Além disso, o uso da estaquia nesta espécie está condicionado à utilização de práticas especiais, como nebulização intermitente e emprego de substâncias promotoras do enraizamento (ácido indolbutírico), enquanto que a mergulhia demonstrou ser uma técnica relativamente simples e económica, apresentando, talvez como único problema, a limitação de espaço físico. 


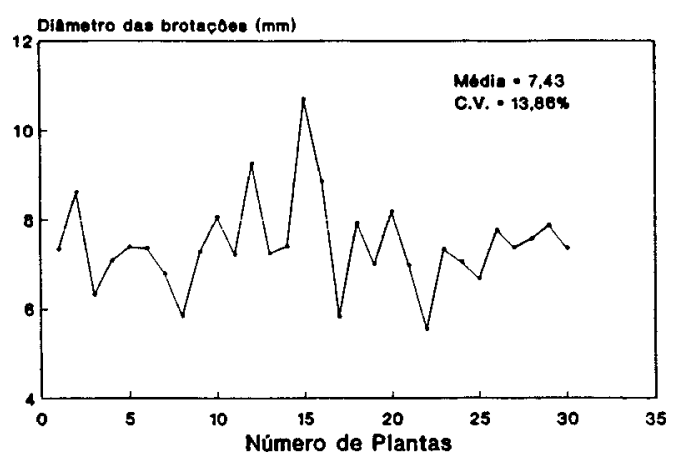

Figura 7 - Diâmetro médio das brotações de plantas de goiabeira serrana multiplicadas por mergulhia.

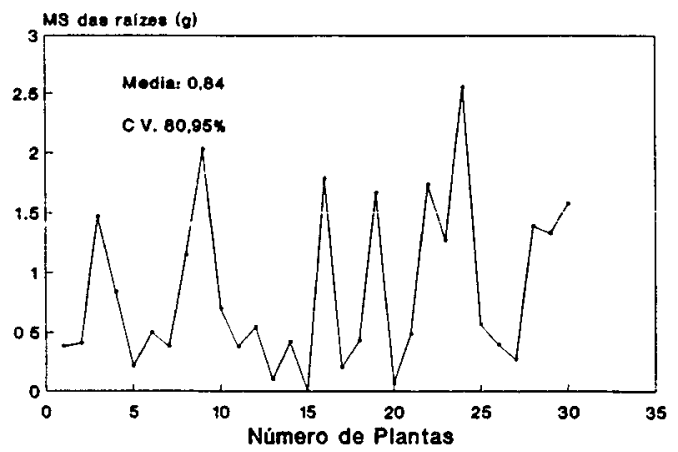

Figura 8 - Peso da matéria seca das raízes de plantas de goiabeira serrana multiplicadas por mergulhia de cepa.

A variável diâmetro das brotações apresentou uma variação desde 5,55 até $10,70 \mathrm{~mm}$ entre plantas (Figura 7), sendo grande a variabilidade dentro de algumas plantas e mais uniforme em outras. Observando o TABELA 1, nota-se que o diâmetro das brotações enraizadas foi significativamente superior ao das brotações nãoenraizadas, com um desvio padrão bem menor. Assim, plantas que apresentaram maior variação no diâmetro das suas brotações tiveram um menor percentual de brotações enraizadas. Foram encontradas correlações significativas entre 0 diâmetro das brotações e as variáveis número de brotações e número e percentagem de brotações enraizadas. A influência negativa da variável diâmetro das brotações sobre $\mathrm{o}$ número $\mathrm{e}$ percentagem de brotações enraizadas ocorreu devido à relação inversa desta variável com o número de brotações, uma vez que o incremento no número de brotações ocasionou um decréscimo no diâmetro médio dos mesmos.

TABELA 1 - Diâmetro médio das brotações enraizadas e não-enraizadas. Pelotas, RS, 1992.

\begin{tabular}{ll}
\hline Brotações & Média \\
\hline Enraizadas & $7,89+1-0,89$ A \\
Não-enraizadas & $5,66+1-2,72$ B \\
\hline
\end{tabular}

Médias seguidas de letra distinta diferem entre si pelo teste TUKEY, ao nível de $1 \%$ de probabilidade.

Segundo vários autores, o diâmetro ideal para o enraizamento de estacas de goiabeira serrana encontra-se entre 7 ou $8 \mathrm{~mm}$ (CACIOPPO, 1988; DUARTE, 1991), enquanto que o diâmetro ideal para a realização da enxertia está numa faixa desde 5 até $10 \mathrm{~mm}$, sendo o ideal entre 8 e $9 \mathrm{~mm}$ (diâmetro de um lápis) (FANKHAUSER, 1985; MIELKE, 1992). Assim, pressupõe-se que um desbaste realizado no momento da amontoa, deixando apenas brotações com diâmetro ao redor de $7 \mathrm{~mm}$, poderá aumentar a correlação existente entre o número de brotações e a percentagem de brotações enraizadas por planta; além de facilitar a execução de técnicas avançadas, como a enxertia de mesa (FANKHAUSER, 1985), realizada sobre porta-enxertos multiplicados vegetativamente.

A multiplicação de porta-enxertos clonais através de mergulhia de cepa também apresentaria entre outras vantagens a seleção de características desejáveis, como tolerância à condições de seca ou alagamento, resistência à doenças ou pragas do solo, ou vigor; práticas já utilizadas em outras fruteiras comerciais (PAL et al., 1981; WESTWOOD, 1982; DRIESSEN \& SOUZA FILHO, 1986; HARTMANN \& KESTER, 1990). Além disso, seguindo-se o procedimento empregado neste experimento, as brotações enraizadas são colhidas no início de agosto, coincidindo exatamente com a época mais favorável à formação de calo e subsequente pega dos enxertos (FANKHAUSER, 1985; CACIOPPO, 1988; MIELKE, 1992). 
Os dados apresentados e discutidos neste trabalho demonstram a possibilidade da utilização da mergulhia de cepa para a multiplicação vegetativa da goiabeira serrana, além de levantar a discussão de alguns fatores interessantes, como o fato de ter ocorrido um percentual relativamente elevado de enraizamento na maioria das plantas utilizadas, sem o emprego de substâncias promotoras do enraizamento (ácido indolbutírico), tão necessário ao enraizamento de estacas semilenhosas nesta espécie (IVEY, 1979, KULIEV \& BABAEV, 1989; COUTINHO et al., 1991; DUARTE, 1991). A ausência de correlações significativas existentes entre teor de clorofila, área foliar e diâmetro das brotações com a matéria seca das raízes, indica que outros fatores, além do estado nutricional das plantas, devem ter influenciado sobre esta variável. Assim, é bem provável que diferentes combinações entre auxinas e cofatores do enraizamento, estimulados pelo suprimento constante de elementos minerais e pela presença do sistema radicular, tenham sido as causas das variações ocorridas na emissão e desenvolvimento de raízes nas brotações das diferentes plantas utilizadas, assim como do sucesso obtido com a utilização desta técnica sem a necessidade do emprego de promotores do enraizamento.

\section{CONCLUSÕES}

a) As maiores variações entre plantas foram observadas para matéria seca das raízes, número de brotações enraizadas, número de brotações e percentagem de brotações enraizadas;

b) as variáveis teor de clorofila, área foliar e diâmetro das brotações não apresentaram influência sobre a matéria seca das raízes;

c) o incremento no número de brotações causou um incremento no número de brotações enraizadas, entretanto, não apresentou influência sobre a percentagem de brotações enraizadas;

d) o aumento no número de brotações por cepa ocasionou um decréscimo no diâmetro médio das mesmas;

e) é possível multiplicar plantas de goiabeira serrana através de mergulhia de cepa, obtendo-se bons resultados mesmo sem o uso de substâncias promotoras do enraizamento.

\section{AGRADECIMENTOS}

Aos Pesquisadores do Centro Nacional de Pesquisa de Fruteiras de Clima Temperado/ EMBRAPA, M.Sc. Ailton Raseira e Dr. Darcy Camellato, pelo material experimental e equipamento gentilmente fornecidos.

\section{REFERÊNCIAS BIBLIOGRÁFICAS}

ADRIANCE, G.W.; BRISON, F.R. Propagation of Horticultural plants. New York: McGraw-Hill, 1955.298p

ARNON, D. Copper enzymes in isolated chloroplasts; polyphenoloxidasein Beta vulgaris. Plant Physiology, Rockville, v.24, p.1-15, 1949.

BENINCASA, M.M.P. Análise do crescimento de plantas (noçōes básicas). Jaboticabal: UNESP-FCAV, 1988. $41 \mathrm{p}$.

BRASIL. Divisāo Nacional de Pesquisas do Ministério da Agricultura. Levantamento de reconhecimento dos solos do Estado do Rio Grande do Sul. Boletim técnico da Divisão de Pesquisa Pedológica do Ministério da Agricultura, Recife, n.30, 1973. 431 p.

CACIOPPO, O. La Feijoa. Madrid: Mundi-Prensa, 1988. 85p.

COUTINHO, E.F.; MIELKE, M.S.; ROCHA, M.S.; DUARTE, O.R. Enraizamento de estacas semilenhosas de fruteiras nativas da família Myrtaceae com o uso do ácido indolbutírico. Revista Brasileira de Fruticultura, Cruz das Almas, v.13, n.1, p.167172, 1991 .

DRIESSEN, A.C.; SOUZA FILHO, J.J.C. Produção de mudas. In: EMPASC. Manual da Cultura da Macieira. Florianópolis, 1986. p.202-223.

DUARTE, O.R. Efeito da época e do ácido indolbutírico (AIB) no enraizamento de estacas semilenhosas de goiabeira serrana (Feijoa sellowiana Berg). Pelotas, 1991. 82p. Dissertação (Mestrado) Faculdade de Agronomia "Eliseu Maciel", Universidade Federal de Pelotas.

DUBOIS, L.A.M. Variation for the adventitious root formation of dwarf rose cuttings, with regard to the leaf area. In: INTERNATIONAL HORTICULTURAL CONGRESS, 23., Florence, 1990. Abstracts of Contributed Papers, 1., Oral. Firenze, 1990. p.193.

FACHINELLO, J.C.; NACHTIGAL, J.C. Propagação da goiabeira serrana (Feijoa sellowiana Berg) através de mergulhia de cepa. Scientia Agricola, Piracicaba, v.49, n.1, p.37-39, 1992. 
FANKHAUSER, I. Propagating feijoa by bench grafting. International Plant Propagator's Society. Combined Proceedings of Annual Meetings. Seattle, v.34, n.401-403, 1985.

HARTMANN, H.T.; KESTER, D. Propagación de plantas: principios y practicas. México: Continental, 1990. 760p.

IVEY, I.D. Feijoas: selection and propagation. International Plant Propagator's Society. Combined Proceedings of Annual Meetings. Seattle, v.29, p.161-168, 1979.

KULIEV, F.A.; BABAEV, M.M. Studies on the vegetative propagation of feijoa. Subtropcheskie kul'tury, Berlin, v.5, p.127-132, 1983.

MIELKE, M.S. Multiplicação da goiabeira serrana (Feijoa sellowiana Berg) através de enxertia. Pelotas, 1992. 46p. Dissertação (Mestrado) - Faculdade de Agronomia "Eliseu Maciel", Universidade Federal de Pelotas.

MOHAMMED, S. Macropropagation of tropical fruit crops and its improvement. Fruits, Paris, v.39, n.12, p.15-22, 1984.
PAL, R.N.; SRIVASTAVA, R.P.; SINGH, N.P.; CHADHA, K.L. Clorophylls, dry matter and leaf area in relation to vigour of different mango rootstocks. Indian Joumal of Horticulture, Bangalore, v.38, p.9-15, 1981.

QUAMME, H.A.; BROWNLEE, R.T. Stool layering ability of thirty-one apple rootstocks cultivars. Fruit Varieties Journal, University Park, v.44, n.3, p.165$169,1990$.

RASEIRA, A.; RASEIRA, M.C.B. Fruteiras nativas de clima temperado. HortiSul, Pelotas, v.1, n.2, p.47-51, 1989.

SILVA, I.C. Propagação vegetativa: aspectos morfofisiol6gicos. Belem: CEPLAC, 1985. 26p. (Boletim Técnico, 4)

WESTWOOD, M.N. Fruticultura de Zonas Templadas. Madrid: Mundi-Prensa, 1982. 461p.

Enviado para publicação 15.06 .93

Aceito para publicação em 28.09 .93 